\title{
Importance of Eustachian Tube Function Assessment in Tympanoplasty in Children
}

\author{
Mohammed Gamal Abdallah ${ }^{1, *}$ M.B.B.Ch, Ali Abdallah Abdel Rahman ${ }^{1}$ MD, \\ Ahmad Mohamed Mahmoud ${ }^{2}$ MD, Mohamed Kamel Aleawdi ${ }^{1}$ MD.
}

\author{
* Corresponding Author: \\ Mohammed Gamal Abdallah \\ $\underline{\text { mohgamal1312@gmail.com }}$
}

Received for publication May 27, 2020; Accepted November 19, 2020; Published online November 19, 2020.

Copyright 2020 The Authors published by Al-Azhar University, Faculty of Medicine, Cairo, Egypt. All rights reserved. This an openaccess article distributed under the legal terms, where it is permissible to download and share the work provided it is properly cited. The work cannot be changed in any way or used commercially.

doi: 10.21608 /aimj.2020.30333.1228

${ }^{I}$ Department

Otorhinolaryngology, Faculty of Medicine, Al-Azhar University, Egypt

${ }^{2}$ Department of Audiology, Faculty of Medicine, Al-Azhar University, Egypt

\begin{abstract}
Background: The Eustachian tube is a tube that links the nasopharynx to the middle ear. It is a part of the middle ear. In adult humans the Eustachian tube is approximately $35 \mathrm{~mm}$ (1.4 in) long. It aerates the middle ear system and clears mucus from the middle ear into the nasopharynx.

Aim of the work: The aim of this study is to know importance of Eustachian tube function assessment in tympanoplasty in children.

Patient and methods: This study included thirty patients selected from the Outpatient Clinic, ENT Department, Faculty of Medicine, Al-Azhar University. All the patients had tubotympanic type of chronic suppurative otitis media with central perforation.

Results: Lesion in left side represented $46.7 \%$ among the studied patients. Graft was taken in 23 patients $(76.7 \%)$. In our study, there is statistically significant increase in number of patients attaining good Eustachian tube function, 13 patients had preoperative good ETF versus 23 ones postoperatively. There are statistically non-significant relations between patient gender and preoperative and postoperative ETF.

Conclusion: We can conclude that there is a strong association between ETF and graft uptake. This proves that eustachian tube plays a major role in the graft uptake.

Keywords: Eustachian Tube Function; Tympanoplasty; Children; CSOM.
\end{abstract}

Disclosure: The authors have no financial interest to declare in relation to the content of this article. The Article Processing Charge was paid for by the authors.

Authorship: All authors have a substantial contribution to the article.

\section{INTRODUCTION}

Three main functions of eustachian tube are ventilation and regulation of middle ear pressure, middle ear clearance of secretions, and protection against nasopharyngeal sound pressure and reflux of nasopharyngeal secretions. A normal aerated middle ear cavity and normal antrum are important for middle ear functions. Tympanometry type 2 (Toynbee's test) is an essential tool to assess eustachian tube function (ETF) in perforated tympanic membrane and tympanometry type 1 (William's test) is an essential tool to assess the ETF in intact tympanic membrane ${ }^{\mathbf{1}}$.

The Eustachian tube (ET) plays an important role in maintaining normal aeration of the middle ear. Inflammation in middle ear disease is related to ET dysfunction, and postoperative restoration of middle ear integrity and hearing are closely related to ET function in patients with chronic ear disease. ${ }^{2}$

Chronic otitis media is typically a persistent disease of middle ear cleft with permanent abnormalities of tympanic membrane (TM), insidious in onset, often capable of causing severe destruction and irreversible sequel and clinically manifests with discharge from ear and hearing loss. Eicherwald and Stroder ${ }^{(3)}$ stated that the Eustachian tube (ET) dysfunction is believed to be important in the pathogenesis of chronic otitis media. ${ }^{3}$

Chronic suppurative otitis media (CSOM) is of two types tubotympanic (mucosal) and atticoantral (squamous). The atticoantral type (squamous type) is due to cholesteatomatous lesions. Tubotympanic type (mucosal) is mainly due to infection from the oropharynx and the nasopharynx and sources like Gastroesophageal reflux diseases travels via the eustachian tube into the middle ear. Not all patients with oropharyngeal and nasopharyngeal sources of infection develop CSOM. ${ }^{4}$

Tympanoplasty is an operation performed to eradicate disease from the middle ear and to reconstruct, if possible, the hearing mechanism. The reconstruction usually involves: closing tympanic membrane perforation, maintaining a well-aerated middle ear cavity, reconstructing the ossicular chain, or any combination of the above. 
Repair of tympanic membrane perforations with most accepted techniques reaches a success rate over $90 \%$. Various graft materials such as temporalis muscle fascia, perichondrium, cartilage, fat, fascia lata, vein, and skin have been used to repair tympanic membrane perforations. The most commonly used graft materials in tympanoplasty is the temporalis muscle fascia, and the success rate is reported to be $60 \%$ to $99 \%$ in adults and $35 \%$ to $94 \%$ in children. ${ }^{6}$

However, the technique necessarily invokes lifting of a tympano-meatal flap for fixation of the graft, with its inherent tendency to provoke bleeding that sometimes impairs visualization and causes flap tears, particularly with neophyte surgeons. Also subsequent packing may cause displacement of the graft, which may contribute to the failure rate. In addition, the flap elevation and subsequent packing introduce a degree of morbidity. ${ }^{7}$

The aim of this study is to know importance of eustachian tube function assessment in tympanoplasty in children.

\section{PATIENTS AND METHODS}

This study included thirty patients selected from the Outpatient Clinic, ENT Department, Faculty of Medicine, Al-Azhar University. All the patients had tubotympanic type of chronic suppurative otitis media with central perforation.

Inclusion criteria: Age from 10-18 years, both males and females and patients presented with chronic otitis media with central perforation.

Type of the study: Prospective study in patients with tubotympanic type of chronic suppurative otitis media with central perforation. They are referred for tympanoplasty, they were performed in operative theater by the same surgeon.

Ethical approval and written informed consent: an approval of the study was obtained from Al- Azhar University academic and ethical committee. Every patient signed an informed written consent for acceptance of the operation.

\section{All patients were subjected to the following:}

\section{- Detailed history taking.}

- Clinical examination: History of past ventilation tube, allergy, asthmatic tendencies and ear trauma, history of noise exposure and the duration of such exposure, if the patient undergone tympanic membrane surgery on the same ear previously, and history of any bleeding tendency, otoscopic assessment of the ear for infection; granulation tissue, TM perforation and middle ear mucosal status.

- Investigations: Tympanometry was done before surgery and after operation by 3 months.

- Preoperative Assessment of ET function by type 2 Tympanometry.

- Postoperative assessment of ET function by type 1 Tympanometry 3 months after operation.
- Preoperative routine investigations for surgical fitness included CBC, PT, PTT, INR, BT, CT, RBS, ASGOT, ASGPT, S.UREA, S.CREATININE and ECG.

\section{Surgical procedures:}

- All operations were performed under general anesthesia, we were used underly technique.

- Xylocaine 1\% with adrenalin 1: 100000 infiltrate into postaural area and the meatal skin.

- The perforation edges are refreshed using fine probe to stimulate growth of tympanic membrane remnants over the graft.

- Post-aural incision, followed by elevation of tympano-meatal flap.

- Temporalis fascia harvested, cleaned from muscle fibers and left to dry for few minutes before use.

- Skin flap reposition and pledges of gel-foam put on the graft and the ear were packed.

- The patients were then called after 3 months, Eustachian tube function by tympanometry was again repeated in all the patients. In patients with intact tympanic membrane, a tympanometric assessment was made by measuring the middle ear pressure first and subsequently twice again after asking the patients to swallow in an attempt to make the Eustachian tube patent and functioning.

- A patient in whom the graft was failed to take up and the perforation was persisted was subjected to Eustachian tube function for perforated tympanic membrane, the opening and the residual pressure of that was noted.

\section{Postoperative management:}

Patients were started on suitable antibiotics. Antibiotics were given for 1 week along with analgesics, antihistamine, and multivitamins. Mastoid bandage was changed on the 2nd postoperative day and dressing applied. The sutures were removed on the 7th postoperative day. Patients were reviewed 2 weeks after discharge and second and third review on 1st and 3rd month postoperatively. Patients were evaluated postoperatively using otoscopy.

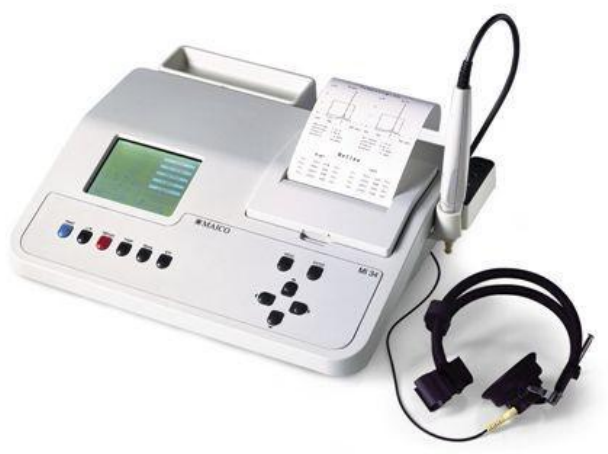

Figure 1: The device used: Maico Mi-34 tympanometer. 


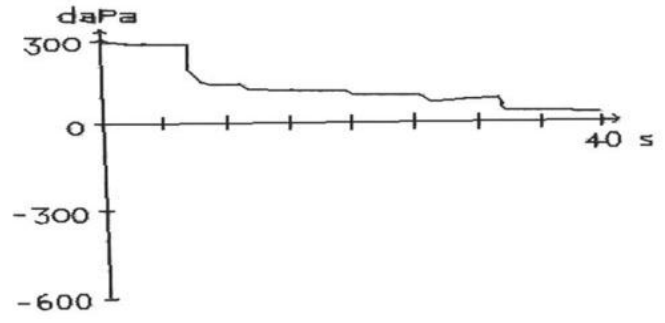

Figure 2: Normal Eustachian tube function.

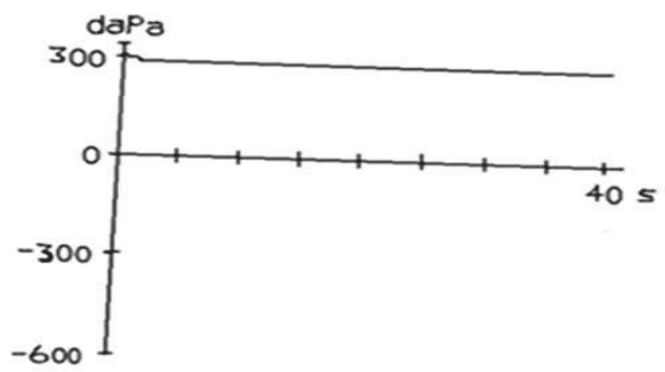

Figure 3: Impaired Eustachian tube function.

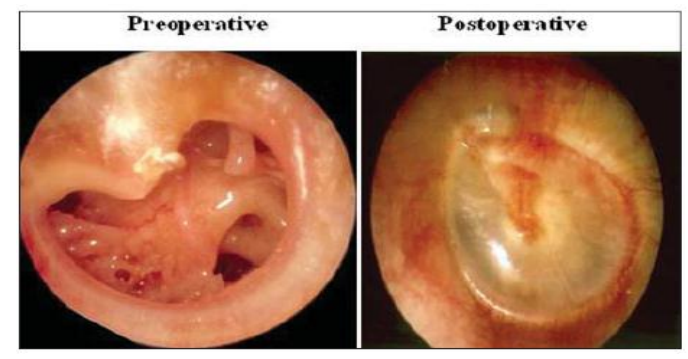

Figure 4: Endoscopic picture of pre- and postoperative tympanic membrane, Toynbee's test partially impaired ET function, Toynbee's test totally impaired ET function, Eustachian tube function and graft status.

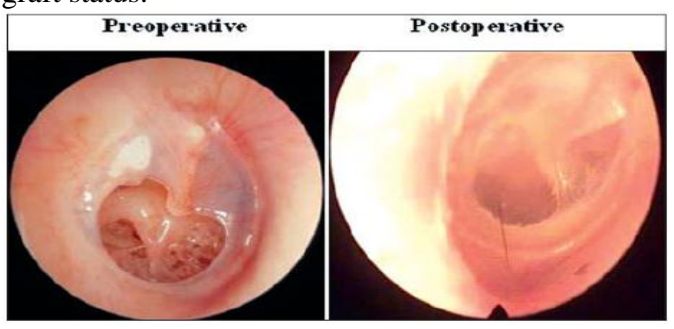

Figure 5: Microscopic picture of pre- and postoperative tympanic membrane.

On the basis of ear findings following tympanoplasty, patients were divided into good outcome (defined as healed graft with good middle ear function) and poor outcome (graft failure or perforation secondary to otitis media during follow up period).

Statistical analysis: Recorded data were analyzed using the statistical package for social sciences, version 20.0 (SPSS Inc., Chicago, Illinois, USA). Quantitative data were expressed as mean \pm standard deviation (SD). Qualitative data were expressed as frequency and percentage.
The following tests were done:

- Independent-samples t-test of significance was used when comparing between two means.

- Chi-square $\left(\mathrm{x}^{2}\right)$ test of significance was used in order to compare proportions between two qualitative parameters.

- The confidence interval was set to $95 \%$ and the margin of error accepted was set to $5 \%$. The $\mathrm{p}$ value was considered significant as the following:

- Probability (P-value)

$$
\begin{aligned}
& \text { P-value }<0.05 \text { was considered } \\
& \text { significant. } \\
& \text { - P-value <0.001 was considered as } \\
& \text { highly significant. } \\
& \text { - P-value >0.05 was considered } \\
& \text { insignificant. }
\end{aligned}
$$

\section{RESULTS}

\begin{tabular}{|l|c|c|}
\hline \multicolumn{1}{|c|}{ Graft taken } & $\mathbf{N}=\mathbf{3 0}$ & \% \\
\hline Taken & 23 & 76.7 \\
Untaken & 7 & 23.3 \\
\hline
\end{tabular}

Graft was taken in 23 patients (76.7\%)

Table 1: Distribution of the studied patients according to graft taken.

\begin{tabular}{|l|l|l|l|l|}
\hline $\begin{array}{l}\text { Eustachian } \\
\text { tube function }\end{array}$ & Poor & Good & Test \\
\cline { 2 - 3 } & $\begin{array}{l}\text { N=24 } \\
(\mathbf{\%})\end{array}$ & $\mathbf{N = 3 6 ( \% )}$ & & \\
\hline Preoperative & $17(70.8)$ & $13(36.1)$ & 8.1 & $0.002^{*}$ \\
\hline Postoperative & $7(29.2)$ & $23(63.9)$ & & \\
\hline
\end{tabular}

Table 2: Change in Eustachian tube function among

\begin{tabular}{|c|c|c|c|c|}
\hline \multirow{3}{*}{$\begin{array}{l}\text { Eustachian } \\
\text { tube } \\
\text { function }\end{array}$} & \multicolumn{2}{|l|}{ Graft } & \multicolumn{2}{|l|}{ Test } \\
\hline & Taken & Untaken & \multirow[t]{2}{*}{$\chi^{2}$} & \multirow[t]{2}{*}{ p } \\
\hline & $\begin{array}{l}\mathrm{N}=23( \\
\%)\end{array}$ & $\mathrm{N}=7(\%)$ & & \\
\hline $\begin{array}{l}\text { Preoperativ } \\
\text { e: } \\
\text { Good }(n=13) \\
\text { Poor }(\mathbf{n}=\mathbf{1 7})\end{array}$ & $\begin{array}{l}13 \\
(56.5) \\
10 \\
(43.5) \\
\end{array}$ & $\begin{array}{l}0(0) \\
7(100)\end{array}$ & Fisher & $\begin{array}{l}0.01 \\
*\end{array}$ \\
\hline $\begin{array}{l}\text { Postoperati } \\
\text { ve: } \\
\text { Good }(n=23) \\
\text { Poor }(n=7)\end{array}$ & $\begin{array}{l}23 \\
(100) \\
0(0) \\
\end{array}$ & $\begin{array}{l}0(0) \\
7(100)\end{array}$ & Fisher & $\begin{array}{l}<0.0 \\
01 * *\end{array}$ \\
\hline P (MCN) & $0.002 *$ & & & \\
\hline
\end{tabular}
thee studied patients.

There is statistically significant increase in number of patients attaining good Eustachian tube function thirteen patients had preoperative good ETF versus 23 ones postoperative).

Table 3: Relation between graft taking and Eustachian tube function pre and postoperatively.

There is statistically significant relation between graft taken and preoperative ETF (43.5\% in group of

(1)


patients had graft taken versus all patients with no graft taken had poor ETF).

There is statistically significant relation between graft taken and postoperative ETF (all patients with graft had good ETF while all patients with no graft had poor ETF).

In our study lesion in left side represented $46.7 \%$ among the studied patients. Graft was taken in 23 patients $(76.7 \%)$

On assessing change in ETF in each group individually, there is significant improvement in Eustachian tube function in the group with graft.

\section{DISCUSSION}

The aim of this study is to know importance of Eustachian tube function assessment in tympanoplasty in children. This study was carried out on 30 patients with tubotympanic type of chronic suppurative otitis media with central perforation. They are referred for tympanoplasty.

In our study, there is statistically significant increase in number of patients attaining good Eustachian tube function, thirteen patients had preoperative good ETF versus 23 ones postoperatively. There are statistically non-significant relations between patient gender and preoperative and postoperative ETF.

Earlier studies of ETF have mainly employed the technique of politzeration, which is insensitive and difficult to quantitate. Cohn et al. ${ }^{8}$ assessed ETF by using impedance audiometry (Toynbee's test). Those with normal ETF showed a graft uptake of $95 \%, 75 \%$ graft uptake in partially impaired ETF, and $69 \%$ graft uptake in totally impaired ETF.

Palva ${ }^{9}$ worked out quantitative methods for measuring preoperative tubal function in patients with perforation of the drum. These methods have subsequently been used by a number of authors. They are based upon the capability of the eustachian tube to equilibrate an induced negative or positive pressure in the middle ear by deglutition. However, these methods do not evaluate one of the most important function of the eustachian tube, the drainage function, which may be impaired even though the tube is anatomically open.

Sen et al. ${ }^{10}$ assessed ETF by using impedance audiometry. Those with normal ETF a graft uptake of $80 \%, 80 \%$ graft uptake in partially impaired ETF, and $66 \%$ graft uptake in totally impaired ETF.

Priya et al. ${ }^{11}$ evaluated the treatment outcome of chronic suppurative otitis media (CSOM tubotympanic type) in relation to eustachian tube dysfunction. The study group comprised of 100 patients who were diagnosed to have CSOM of tubotympanic type. They proved that there was no association between the graft uptake and age and gender.

In our study, there are statistically significant relations between side of lesion and preoperative and postoperative ETF. Also, there is statistically significant relation between site of lesion and postoperative ETF. On pair-wise comparison, the difference is significant between patients with anterior and posterior perforations. There is statistically significant relation between graft taken and preoperative and postoperative ETF. On assessing change in ETF in each group individually, there is significant improvement in Eustachian tube function in the group with graft. Priya et al. ${ }^{11}$ proved that there was no association between the graft uptake and type of perforation and duration of ear discharge.

The ETF has been the center of focus as a prognostic factor because of its presumed primary role in the pathogenesis of otitis media and in the aeration of middle ear cavity. The ETF is the most important determinant of surgical outcome in patients with CSOM (tubotympanic type). ${ }^{12}$

A properly functioning Eustachian tube is an integral part of a normally functioning middle ear and the existence of good tubotympanic mucociliary drainage constitutes a favorable prognostic factor in the outcome of reconstructive surgery of the middle ear. A functioning eustachian tube is an integral part of a normal middle ear and is thus an essential requirement for optimum results in tympanoplastic operations. A preoperative test of tubal function is, therefore, of great interest, especially if such a test provides a possibility of estimating the chances of achieving a satisfactory result of tympanoplasty. ${ }^{13}$

Paparella et al. ${ }^{14}$ found that diseased or edematous mucosa had a graft uptake of $50 \%$ when compared with dry middle ear mucosa which showed an uptake of $69.5 \%$ and the preoperative factors such as dry or wet ear, site of perforation do not affect the graft take up rate. They found that no relationship between mastoid pneumatization and graft uptake.

Bluestone et al. ${ }^{15}$ reported the results of a prospective study of 45 children (51 ears) which was undertaken to determine which, if any, detectable and controllable pre or intraoperative parameters might predict the outcome of tympanoplasty surgery. The overall success rate of tympanoplasty in children was $35 \%$. The success of tympanoplasty was not related to graft placement, although the laterally placed grafts had a higher take rate $(67 \%)$ than grafts placed medially (49\%). Preoperative measures, such as the assessment of Eustachian tube function using the modified inflation-deflation test and tympanometric evaluation of the contralateral ear, failed to predict the success of tympanoplasty. Tympanoplasty universally failed in the ears in which an acquired cholesteatoma was present. Children remain uncertain candidates for tympanoplasty surgery since, as a group, their Eustachian tube function is not as good as that of adults.

Manning et al. ${ }^{16}$ investigated the role of Eustachian tube function on the outcome in 63 ears (56 children) undergoing tympanoplasty for central perforations. In 49 ears $(78 \%)$, the graft took; of these, 33 had good middle-ear function, 8 developed persistent or recurrent otitis media, and 8 had severe retraction or atelectasis. There was a significant association between outcome and preoperative tubal function as determined by combining the active and passive 
function parameters. However, the prognostic value of tubal function testing was low; predictive values for success and lack of success being $68 \%$ and $56 \%$, respectively. Other factors, such as graft placement (medial or lateral), contralateral ear status, and child's age, were not associated with outcome. Good Eustachian tube function was shown to predict good outcome, but poor tubal function was not helpful in predicting poor outcome.

Prasad et al. ${ }^{17}$ evaluated the mucociliary function of the ET by saccharin and methylene blue test, and compared the outcome of surgery with normal and abnormal ET functions. They concluded that the saccharin test is a simple, cost-effective, and valuable diagnostic tool to assess the mucociliary function of the ET. The outcome of middle ear surgery would be a success in normal ETF, whereas in partial dysfunction the outcome need not necessarily be a failure.

Priya et al. ${ }^{11}$ proved that the eustachian tube plays a major role in the uptake of graft in CSOM patients. Simple mastoidectomy in all tympanoplasties is a good practice. It increases the middle ear cleft space and that this is the good idea if there is compromised ETF.

\section{CONCLUSION}

Tubal function treated as categorical data was significantly associated with the outcome of tympanoplasty. ETF groups according to inflationdeflation and forced-response test results were predictive of the operation's success but not failure. No doubt, tubal function is but one factor in an equation of outcome determinators including surgical technique, site of perforation and susceptibility to otitis media.

We can conclude that there is a strong association between ETF and graft uptake. This proves that eustachian tube plays a major role in the graft uptake, long-term follow up is needed and more studies on large numbers of patient.

\section{REFERENCES}

1. Andreasson L and Harris S. Tympanoplasty and Eustachian tube function. Clin Otolaryngol Allied Sci, 1978; 3: 421-30.

2. Lin AC and Messner AH. Pediatric tympanoplasty: factors affecting success. Curr Opin Otolaryngology Head Neck Surgery, 2008; 3: 64-8.

3. Eicherwald HF and Stroder J. Practical Pediatric Therapy. Florida: VCH Publishers Inc., 1985; 522-3.

4. Paparella MM, Shumrick DA, Gluckman JL et al. Physiology of middle ear and Eustachian tube. Otolaryngology, 1991; 1: 163-97.
5. Ferekidis EA, Nikolopoulos CDEF, Kandiloros DC, et al. Chondrotympanoplasty: A modified technique of cartilage graft tympanoplasty. Med Sci Monit, 2003; 9(2): CR73-8.

6. Mohamed SH, Khan I and Hussain SS. Is cartilage tympanoplasty more effective than fascia tympanoplasty? A systematic review. Otol Neurotol, 2012; 33(5): 699-705.

7. Eavey RD. Inlay tympanoplasty: Cartilage butterfly technique. Laryngoscope, 1998; 108: 657-61.

8. Cohn AM, Schwaber MK, Anthony LS et al. Eustachain tube function and tympanoplasty. Ann Otol, 1979; 88: 339-47.

9. Palva T. Surgical treatment of chronic middle ear disease, myringoplasty and tympanoplasty. Acta Otolaryngol, 1987; 104: 179-84.

10. Sen S, Guha S, Biswas A et al. A comparative study of methods of evaluation of Eustachian tube functions in chronic otitis media. Indian $J$ Otol, 1998; 4: 147-9.

11. Priya K, Karthikeyan $\mathrm{P}$ and Coumare VN. Evaluation of Eustachian tube functions in chronic suppurative otitis media (tubotympanic type) with reference to its treatment outcome. Indian J Otol, 2012; 18: 179-83.

12. Tos M. Importance of Eustachian tube function in middle ear surgery. Ear Nose Throat J, 1998; 77: 744-7.

13. Gimenez F and Algarra M. The prognostic value of mucociliary clearance in predicting success in tympanoplasty. J Laryngol Otol, 1993; 107: 895-7.

14. Paparella M, Kurein SR, Christolyte S et al. Inflation-deflation test as a predictor of aditus patency in patients with chronic suppurative otitis media. Indian J Otolaryngol Head Neck Surg, 2009; 61: 169-72.

15. Bluestone CD, Cantekin EI and Douglas GS. Eustachian tube function related to the results of tympanoplasty in children. The Laryngoscope, 1979; 89(3): 450-8.

16. Manning SC, Cantekin EI, Kenna MA et al. Prognostic value of Eustachian tube function in pediatric tympanoplasty. Laryngoscope, 1987; 98: 1012-6.

17. Prasad KC, Hegde MC, Prasad SC et al. Assessment of Eustachian tube function in tympanoplasty. Otolaryngology, Head and Neck Surgery, 2009; 140(6): 889-93.

(1)

